\title{
Study of the in vitro Anti-bacterial Susceptibility of the Commercially Available Antibiotics in Suspension or Solution Forms Collected within Dhaka Metropolis
}

\author{
Asma Akter Bhuiyan, Mehran Mosharraff Hossain Niloy, Anamika Chakrabarty, Syeda Muntaka Maniha, \\ Rashed Noor $^{1 *}$ \\ ${ }^{I}$ School of Life Sciences (SLS), Independent University, Bangladesh (IUB), Plot 16, Block B, Aftabuddin Ahmed Road, Bashundhara, Dhaka 1229, Bangladesh
}

\begin{abstract}
Consumption of a range of antibiotics upon bacterial infections is a common chemotherapeutic practice. Current study attempted to detect the in vitro anti-bacterial activities of such finished medicaments against some of the selected bacterial strains in order to examine their sustainable effectiveness against microorganisms. A total of six categories of samples were randomly collected from different pharmacies within the city of Dhaka. The antibacterial susceptibility tests were conducted employing the Kirby-Bauer (agar well diffusion) method. The test bacterial strains used in this study were Escherichia coli, Staphylococcus aureus, Bacillus cereus, Pseudomonas aeruginosa and $P$. putida and $P$. fluorescence. While $E$. coli was found to be sensitive towards all the antibiotics used, others showed resistance to a significant extent. flucloxacillin, cephradine and salbutamol were noticed to be completely inactive against Pseudomonas species. Besides, the salbutamol was found only to suppress the growth of $E$. coli but the other five test organisms were completely resistant against this antibiotic solution.
\end{abstract}

Keywords: Antibiotics suspension/solution, antibacterial susceptibility

\section{Introduction}

Upon bacterial infection, an array of antibiotics has long been used to combat the infectious agent or sometimes the specific consortium of pathogens causing the disease. Maximum children administer antibiotics in liquid forms; i.e., the dry powder of antibiotics is usually reconstituted with the prescribed amount of sterile, cold water thereby forming the suspension of antibiotics ${ }^{1}$. Precise reconstitution to achieve the appropriate homeostatic drug concentration as well correct the dose determination for antibiotic uptake is of significant issue during the antibiotic treatment ${ }^{2}$. During the industrial manufacturing of such antibiotics, the total quality management (TQM) starting from the raw materials ending up to the finished products strictly adhere to the good manufacturing practice (GMP) that is prescribed usually by the food and drug administration (FDA). The final microbiological quality of the finished products together with their antibacterial activities are of clinical significance as comprehensively outlined by the European Pharmacopoeia (EP), the British Pharmacopoeia (BP) and the United States Pharmacopoeia (USP) ${ }^{3}$. Indeed, the industrial manufacturing of the antibiotics principally based on the large scale production of microorganisms, which later convert the corresponding raw materials into the precise antibiotics by a process called fermentation which further undergoes the downstream processing for the recovery of antibiotics ${ }^{3-4}$.
Though antibiotics have long been used as the effectual chemotherapeutic agents for the mitigation of almost all diseases; however, the unfortunate incidence of drug-resistance has become a major health concern around the world ${ }^{5-7}$. A number of antibiotics are becoming lesseffective against a range of pathogenic bacteria which is alarming in course of mass public health since such a situation would lead to morbidity and mortality due to simple pathogenic infection onward ${ }^{3,8}$. Now a days the occurrence of the multi-drug resistant microorganisms as well as the prevalence of methicillin-resistant S. aureus (MRSA), vancomycin-resistant $S$. aureus (MRSA),vancomycin-resistant Enterococcus species, extended-spectrum ${ }^{2}$-lactamase producing bacteria are not unlikely ${ }^{9-13}$.

Another aspect of clinical concern regarding antibiotics underlies the basis of the stability of the finished products as well as the rate of market complaints. After the manufacturing and packaging of the medicaments, products are distributed in the market with a certain date of expiry during which the products are supposed to be active (in terms of killing effect) against specified microorganisms. Usually pharmaceutical industries are supposed to have such monitoring function inclusive of the finished product validation and the compliance department dealing with the market complaints (if any). This is really effective for maintain the finished product regulation in terms of quality. It's not unlikely that microorganisms may be capable of utilizing the substrates

*Corresponding author:

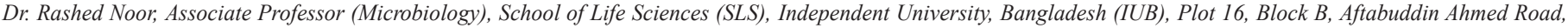
Bashundhara, Dhaka 1229, Bangladesh. Cell: +8801749401451, E-mail: rashednoor@iub.edu.bd 
or active ingredients used in antibiotics which in turn would degrade the potential to kill the disease causing microorganisms ${ }^{14-}$ 15. Based on this rationale, current study was designed in a relatively small scale to examine the effectiveness of some commonly used antibiotic suspensions. The results of such laboratory studies are expected to add certain validity to the given knowledge on the bactericidal activity of the antibiotics intended to be used as suspensions. Moreover, test of anti-bacterial susceptibility also infers the microbial ecology of human host versus their pure culture forms in vitro. Since the microbial growth is known to be significantly higher in the laboratory nutrient media than their natural counterpart (infecting hosts), it's not unlikely that sometimes some antibiotics can be seen ineffective against some test organisms.

\section{Materials and Methods}

Study area and sampling: A total of six categories of commercial antibiotics were used in this study. Finished products of flucloxacillin (narrow spectrum ${ }^{2}$-lactum antibiotic of penicillin class), cephradine (the first generation cephalosporin antibiotic),ciprofloxacin (a fluoroquinolone drug), cefixime (broad spectrum cephalosporin antibiotic), salbutamol (a racemic mixture), and azithromycin, a macrolide antibiotic(with the appropriate labels of dates of manufacturing and the dates of expiry on the corresponding packs) were collected from the pharmacies within the Dhaka City. Samples were tested in the Microbiology Laboratory of School of Life Sciences (SLS), Independent University, Bangladesh (IUB) for further analysis.

Assay of in vitro anti-bacterial activity: Test of antibacterial susceptibility was conducted by the agar well diffusion technique (Kirby-Bauer Disk Diffusion Method) as described earlier ${ }^{21-25}$. Lawns of five test bacterial suspensions (Escherichia coli, Salmonella species, Staphylococcus aureus, Pseudomonas aeruginosa and $P$. fluorescence cultures) were prepared using the log phase cells (the culture turbidity was compared to the 0.5 McFarland standard equivalent to $10^{5}$ cells $/ \mathrm{mL}$ ) on the MullerHinton agar (MHA) ${ }^{16-18}$. Simultaneously wells were prepared with a borer on the MHA and approximately $10 \mathrm{mg} / \mathrm{mL}$ of the crude samples were introduced into the corresponding wells. Buffer peptone water was used as negative controls while the antibiotic disks of gentamicin $(101 / 4 \mathrm{~g})$ were used as positive control $^{18}$. Plates were then incubated at $37^{\circ} \mathrm{C}$ for 15 hours followed by the observation for the appearance of zones of inhibitions. The zones were measure very carefully with the help of electronic slide calipers in the millimeter $(\mathrm{mm})$ scale; and the results were recorded as susceptible $(\mathrm{S})$, resistant $(\mathrm{R})$ or intermediate resistant $(\mathrm{I})^{16-18}$.

\section{Results and Discussion}

Microorganisms such as E. coli, B. cereus, S. aureus, and to a large extent the pseudomonads are present as ubiquitous as well as in most of the cases in their pathogenic forms; and specific antibiotics (either broad-narrow spectrum) are generally prescribed in order to treat the infections caused by these microorganisms. In the current study, the anti-bacterial activity was conducted to monitor the efficacy of the liquid suspension of different antibiotics against these microorganisms to achieve the in vitro results of their potential to further infer the sustainability of the anti-bacterial activities of the samples used (Table 1). The most frequently infecting bacterium $S$. aureus was found sensitive towards flucloxacillin, ciprofloxacin and cephradine (Figure 1)while the other suspensions were not found be that much effective towards this strain (Table 1). The most ubiquitous $P$. auruginosa was found to be sensitive towards azithromycin, cefixime, ciprofloxacin (Figure 1, Table 1). E. coli was noticed to be completely sensitive to all the suspensions of antibiotics used while the other test species have shown comparatively diverse results towards different antibiotics (Figure 2, Table 1). Similarly, B. cereus was found to be sensitive to cefixime, flucloxacillin and ciprofloxacin, while but azithromycin suspension was noticed to be intermediately effective (Figure 2, Table 1).

Indeed, the three strains of Pseudomonas employed in this study provided various sizes of zones of inhibition against all the antibiotics used (Table 1). Comparatively $P$. auruginosa and $P$. fluorescence were found to be more sensitive to azithromycin, cefixime, ciprofloxacin whereas $P$. putidasurprisingly showed resistant against cefixime, flucloxacillin and cephradine (Figure 3 , Table 1). The antibiotic solution (not suspension) salbutamol was noticed to be seemingly effective for $E$. coli but other microorganisms were found to be resistant against this solution (Table 1). The incidence of drug-resistance projected through the current study is of significance. S. aureus was noticed to be resistant against cefixime, azithromycine, and salbutamol. $B$. cereus was resistant against cephradine and salbutamol. The drugresistance pattern was most frequent among the Pseudomonas species. P. aeruginosa was found to be resistant against flucloxacillin, cephradine, ciprofloxacin, and salbutamol. $P$. putida showed the resistance against flucloxacillin, cephradine, cefixime, and salbutamol. P. fluorescence was noticed to impart resistance against flucloxacillin, cephradine, and salbutamol (Table 1).

As stated earlier, the current study was designed to deal with the anti-bacterial potential of the finished products which have already passed a range of quality control (QC) and quality assurance (QA) tests and assays from the corresponding manufacturers. Indeed the pharmaceutical companies are in practice to maintain the records of the quality control tests of the raw materials, the in-process checks (IPCs) during manufacturing, packaging and distribution within the market ${ }^{3}$. Interestingly some pharmaceutical companies especially the multi-national ones are well set with the compliance departments to deal with the market complaints regarding the loss of quality of any product(s). However, together with such pharmaceutical regulations for maintaining the quality of the products, the small scale laboratory 
Antibiotics suspension/solution, antibacterial susceptibility

Table 1. Anti-bacterial activities of the food preservatives and spices

\begin{tabular}{|c|c|c|c|c|c|c|c|c|}
\hline Test species & Samples & $\begin{array}{l}\text { Flucloxacillin } \\
\text { (Flucox) } \\
(\mathrm{n}=5)\end{array}$ & $\begin{array}{c}\text { Cephradine } \\
(\text { Lebac) } \\
(\mathrm{n}=5) \\
\end{array}$ & $\begin{array}{c}\text { Ciprofloxacin } \\
\text { (Ciprocin) } \\
(\mathrm{n}=5) \\
\end{array}$ & $\begin{array}{c}\text { Cefixime } \\
(\text { Roxim) } \\
(\mathrm{n}=5) \\
\end{array}$ & $\begin{array}{c}\text { Salbutamol } \\
(\text { Salmolin) } \\
(\mathrm{n}=5)\end{array}$ & $\begin{array}{c}\text { Azithromycin } \\
(\text { Zimax }) \\
(\mathrm{n}=5) \\
\end{array}$ & $\begin{array}{l}\text { GEN } \\
10 \mu \mathrm{g}\end{array}$ \\
\hline & Range & $25 \pm 0.5$ & $29.5 \pm 0.5$ & $24 \pm 0.5$ & $33.5 \pm 0.5$ & $23.5 \pm 0.5$ & $22 \pm 0.5$ & $22.5 \pm 0.5$ \\
\hline & Susceptibility & $\mathrm{S}$ & $\mathrm{S}$ & $\mathrm{S}$ & $\mathrm{S}$ & $\mathrm{S}$ & $\mathrm{S}$ & $\mathrm{S}$ \\
\hline S. aureus & Mean & 37.02 & 22 & 36.5 & 0 & 0 & 0 & 35 \\
\hline & Susceptibility & S & $\mathrm{S}$ & S & $\mathrm{R}$ & $\mathrm{R}$ & $\mathrm{R}$ & $\mathrm{S}$ \\
\hline B. cereus & Mean & 28.06 & 0 & 41.5 & 31.5 & 0 & 15 & 29.75 \\
\hline & Range & $28 \pm 0.5$ & & $41 \pm 0.5$ & $31 \pm 0.5$ & & $14.5 \pm 0.5$ & $29 \pm 0.5$ \\
\hline & Susceptibility & S & $\mathrm{R}$ & $\mathrm{S}$ & $\mathrm{S}$ & $\mathrm{R}$ & I & $\mathrm{S}$ \\
\hline P. aeruginosa & Mean & 0 & 0 & 0 & 50 & 0 & 34.2 & 33 \\
\hline & Range & & $12 \pm 0.5$ & $16.5 \pm 0.5$ & & & $53.5 \pm 0.5$ & $19.5 \pm 0.5$ \\
\hline & Susceptibility & $\mathrm{R}$ & $\mathrm{R}$ & I & $\mathrm{R}$ & $\mathrm{R}$ & $\mathrm{S}$ & $\mathrm{S}$ \\
\hline P. fluorescence & Mean & 0 & 14.02 & 19.5 & 20.3 & 0 & 50.5 & 23.1 \\
\hline & Range & & $14 \pm 0.5$ & $19 \pm 0.5$ & $20 \pm 0.5$ & & $50 \pm 0.5$ & $23 \pm 0.5$ \\
\hline & Susceptibility & $\mathrm{R}$ & $\mathrm{R}$ & $\mathrm{S}$ & $\mathrm{S}$ & $\mathrm{R}$ & $\mathrm{S}$ & $\mathrm{S}$ \\
\hline
\end{tabular}

$\mathrm{S}=$ Susceptible (zone size is equal to more than $18 \mathrm{~mm}$ ); $\mathrm{R}=$ Resistant (zone size is within 14 to $17 \mathrm{~mm}$ ); $\mathrm{I}=$ Intermediate (zone size is equal to less than $13 \mathrm{~mm}$ ); $\mathrm{n}=$ Number of samples; GEN $10 \mu \mathrm{g}=$ Gentamicin $10 \mu \mathrm{g}$ (positive control).

Each of the antibiotic suspensions was tested with the concentration of approximately $10 \mu \mathrm{g} / \mathrm{ml}$.

Experiments were performed five times and the results were found to be reproducible. The inferential statics was done as shown by the mean and range.

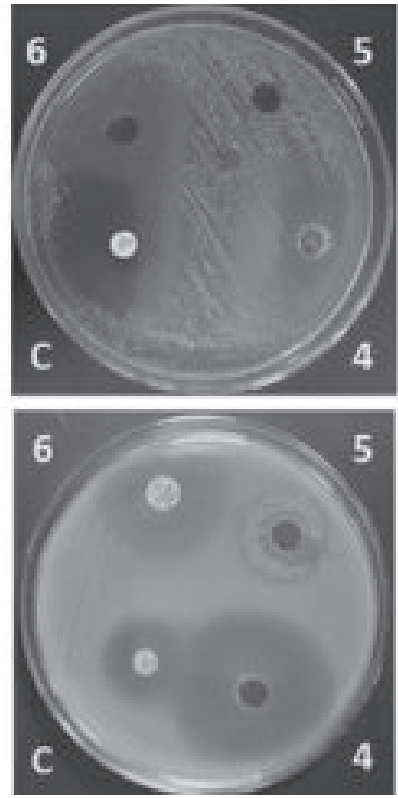

Samples:

1. Flucloxacillin (Fluclox)

2. Cephradine (Lebac)

3. Ciprofloxacin (Ciprocin)

4. Cefixime (Roxim)

5. Salbutamol (Salmolin)

6. Azithromycin (Zimax)

\section{Control:}

\section{Gentamicin $10 \mu \mathrm{g}$}

Figure 1. Anti-bacterial activities of the suspensions of the antibiotics against Staphyloccous aureus and Pseudomonas aeruginosa. Agar well diffusion (Kirby-Bauer disk diffusion method) was used for this study as described in Materials and Methods. Lawns of Staphyloccous aureus and Pseudomonas aeruginosa were prepared on the Muller-Hinton agar (MHA). Approximately $10 \mathrm{~g} / \mathrm{mL}$ of the antibiotic suspension samples were introduced into the wells made on the MHA. Plates were incubated at $37^{\circ} \mathrm{C}$ for approximately 15 hours, and the zones of inhibitions were observed in the millimeter ( $\mathrm{mm}$ ) scale. Results were recorded as susceptible (S), resistant (R) or intermediate resistant (I). 
Bhuiyan et. al.
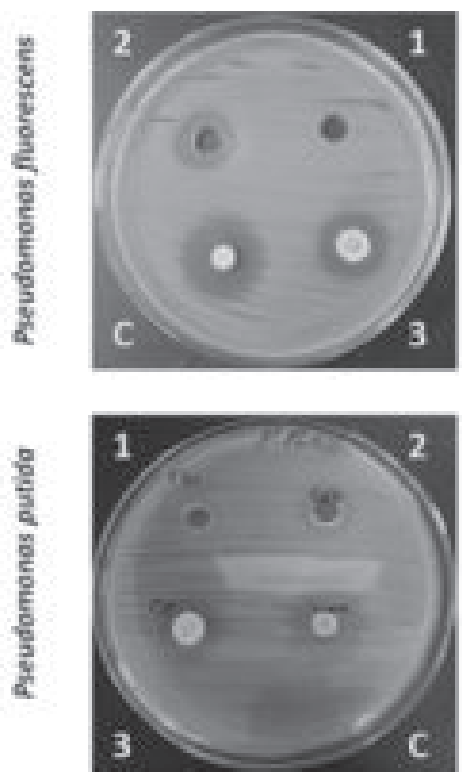
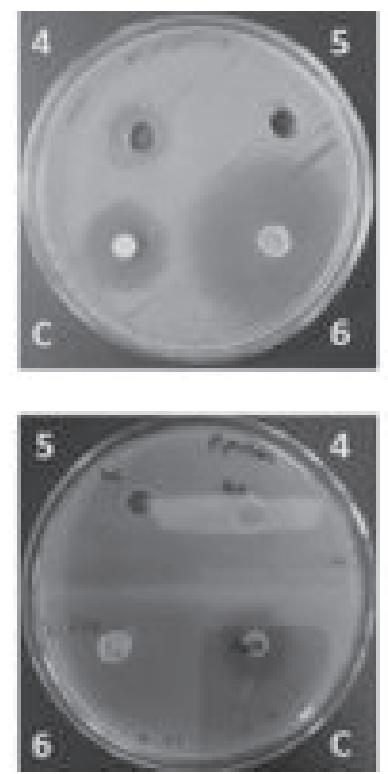

Samples:

\section{Flucloxacillin} (Fluclox)

2. Cephradine (Lebac)

3. Ciprofloxacin (Ciprocin)

4. Cefixime (Roxim)

5. Salbutamol (Salmolin)

6. Azithromycin (Zimax)

Control: Gentamicin $10 \mu \mathrm{g}$

Figure 2. Anti-bacterial activities of the suspensions of the antibiotics against Bacillus cereus and Escherichia coli. As stated in the Materials and Methods, lawns of Bacillus cereus and Escherichia coli were prepared on the MHA; and samples were introduced into the wells (at a concentration of $10 \mathrm{mg} / \mathrm{mL}$ ), followed by incubation at $37^{\circ} \mathrm{C}$ for 15 hours. Zones of inhibitions were observed and the results were recorded as stated in Figure 1.

Figure 3: Anti-bacterial activities of the suspensions of the antibiotics against Pseudomonas fluorescence and P. putida.

based research may also assure the quality retention of the products as well ${ }^{19-20}$. Despoiled quality of the pharmaceutical products may impart complications during treatment of any infection which in turn would raise the consumer dissatisfaction.

\section{Conclusion}

The choice of antibiogram experiment gave a substantial influence to appreciate the in vitro antimicrobial susceptibility against the different control of known pathogens and tracking the emergence of new antibiotic resistant strains of pathogens, and these experiment showed how some of the antibiotics are more sensitive and effective towards some microorganisms and not for others allowing to give a perspective for physician to prescribe certain antibiotics for particular infections. Besides, the drug-resistance traits as observed from the current study especially by the Pseudomonas species needs further investigation by using a large extent of sample size.

\section{Acknowledgement}

Authors are thankful to the Laboratory of Microbiology, School of Life Sciences (SLS) for the logistic support.

\section{References}

1. Al-Ramahi RJ, Zaid AA and Anabousi H. 2015. Problems associated with reconstitution, administration, and storage of antibiotic suspensions for pediatrics: A cross-sectional study in Nablus city, Palestine. BMC Res Notes. 8: 760.

2. Dusdieker LB, Murph JR and Milavetz G. 2000. How much antibiotic suspension is enough? Pediatrics. 106(1): E10.

3. Noor R, Zerin N and Das KK. 2015. Microbiological quality of pharmaceutical products in Bangladesh: Current research perspective. Asian Pac J Trop Dis. 5(4): 264-270.
4. Underwood E. 1998. Good manufacturing practice. In Principles and Practice of Disinfection, Preservation and Sterilization (Russell AD, Hugo WB and Ayliffe GAJ eds.). Blackwell Scientific, Oxford.

5. Noor R and Munna MS. 2015. Emerging diseases in Bangladesh: Current microbiological research. Tzu Chi Med. J. 27(2): 49-53.

6. Dutta S, Hasan MR, Rahman F, Jilani MSA and Noor R. 2013. Study of antimicrobial susceptibility of clinically significant microorganisms isolated from selected areas of Dhaka, Bangladesh. Bangladesh J Med Sci.12(1): 34-42.

7. Noor R, Hossain A, Munshi SK, Rahman F and Kamal SM. 2013. Slide drug susceptibility test for the detection of multidrug-resistant tuberculosis in Bangladesh. J Infect Chemother. 19(5): 818-824.

8. Urmi NJ and Noor R. 2014. Microbiological profile and the anti-bacterial traits of commonly available antacid suspensions in Dhaka metropolis. Int J Pharm Pharmaceut Sci. 6(4): 174-176.

9. Aurin TH, Munshi SK, Kamal SM, Rahman MM, Hossain MS, Marma T, Rahman F and Noor R. 2014. Molecular approaches for detection of the multi-drug resistant tuberculosis (MDR-TB) in Bangladesh. PLOS ONE. 9(6): e99810.

10. Hasan R, Acharjee M and Noor R. 2016. Prevalence of vancomycin resistant Staphylococcus aureus (VRSA) in methicillin resistant S. aureus (MRSA) strains isolated from burn wound infections. Tzu Chi Med J. 28(2): 49-53.

11. Khan SA, Feroz F and Noor R. 2013. Study of extended spectrum ${ }^{2}-$ lactamase producing bacteria from urinary tract infection in Dhaka City, Bangladesh. Tzu Chi Med J. 25(1): 39-42.

12. Zarifan AR, Askari E, Pourmand MR and Nasab MN. 2012. High-level vancomycin-resistant Staphylococcus aureus (VRSA) in Iran: A systematic review. J Med Bacteriol. 1(3-4): 53-61.

13. Ranjbar R and Farahani A. 2019. Study of genetic diversity, biofilm formation, and detection of carbapenemase, MBL, ESBL, and tetracycline resistance genes in multidrug-resistant Acinetobacter baumannii isolated from burn wound infections in Iran. Antimicrob Resist Infect Control. 8: 172. 
14. Russell M. 1996. Microbiological control of raw materials. In Microbial Quality Assurance in Cosmetics, Toiletries and Non-Sterile Pharmaceuticals (Baird RM and Bloomfield SF eds), p 1-47. Taylor \& Francis, London.

15. Parker MS. 2000. Microbiological contamination and preservation of pharmaceutical preparations. In The Science of Dosage From Design. (Aulton ME ed), p 220. Churchill Livingstone, Hong Kong.

16. Cappuccino JG and Sherman N. 1996. Microbiology - A Laboratory Manual. The Benjamin/Cummings Publishing Co, Inc, California.

17. Clinical and Laboratory Standards Institute. Methods for Dilution Antimicrobial Susceptibility Tests for Bacteria That Grow Aerobically:
Approved Standard-Seventh Edition. CLSI, Wayne, Pennsylvania: USA 2006.

18. Sharmin M, Nur IT, Acharjee M, Munshi SK and Noor R. 2014. Microbiological profiling and the demonstration of in vitro anti-bacterial traits of the major oral herbal medicines used in Dhaka Metropolis. SpringerPlus. 3: 739.

19. Hossain MA, Raton AR and Noor R. 2014. Microbiological quality investigation of eye and ear ointments available in Bangladesh. $J$ PharmacognPhytochem. 3(2): 34-38.

20. Khanom S, Das KK, Banik S and Noor R. 2013. Microbiological analysis of liquid oral drugs available in Bangladesh. Int J Pharm Pharm Sci. 5(4): 479-482. 